\title{
Biodegradation of Biaxially Stretched Polyethylene-Starch Composite Films
}

\author{
Teruo NAKashima, Senkichi Nagasaki, ${ }^{*}$ Hiraku ITo, ${ }^{* *}$ Chunye XU, ${ }^{* * *}$ \\ Yuezhen BIN, ${ }^{* * *}$ and Masaru MATSUO ${ }^{* * *, \dagger}$ \\ Department of Information on Living, Kinki University of Toyooka Junior College, \\ 160 Tobera, Toyooka, Hyogo 668-8580, Japan \\ *Faculty of Pharmacentical Science, Toho University, 2-2-1 Miyama, \\ Hunabashi, Chiba 274-8510, Japan \\ ${ }^{* *}$ Department of Clothing Science, Heian Jogakuin College, Nampeidai, \\ Takatsuki, Osaka 569-1092, Japan \\ ${ }^{* * *}$ Department of Textile and Apparel Science, Nara Women's University, \\ Kitauoyanishicho, Nara 630-8506, Japan
}

(Received December 5, 2001; Accepted February 5, 2002)

\begin{abstract}
The biodegradation of biaxially stretched composite films were investigated by using ultra-high molecular weight polyethylene (UHMWPE) with viscosity average molecular weight of $6 \times 10^{6}$ and starch. The films were prepared by gelation/crystallization from dilute solutions of polyethylene (PE), in which starch particles were dispersed. The UHMWPE-starch compositions chosen were 1/1, and 1/5. After stretching, most of starch particles were remained within the composite films. Biodegradative behavior of the composite films was examined by using the samples buried in two kinds of soils, paddy soil and red clay, for 16 months. The weight decrease after the degradation was evaluated and found to be dependent on the starch content, draw ratio of films and kinds of soil. The weight loss of the samples buried in paddy soil was larger than that of the sample buried in red clay. However, the decreases in the storage modulus of the film sample buried in red clay were larger than that buried in paddy soil. This result is of interest since the order of weight decreasing rate for these samples is opposite. Significant morphological changes were observed by scanning electron microscopy (SEM) for the samples buried in red clay. The photograph of the samples buried in red clay revealed that drastic morphological changes occurred not only in the starch domain but also in the PE domain. This phenomenon is in good agreement with the decrease of melting point of polyethylene measured by differential scanning calorimetry (DSC). However, no degradation was observed for the stretched PE sample (1/0) buried in red clay. This indicates that the biodegradation of PE in the composite films buried in red clay is induced by the dispersed starch component.

KEY WORDS Biodegradation / Biaxially Stretched / Gelation/Crystallization / Ultra-High Molecular Weight Polyethylene (UHMWPE)-Starch Compositions / Paddy Soil / Red Clay /
\end{abstract}

Polyethylene (PE) is one of the most abundantly used polymers in the world. However, PE is too stable to be degraded by the attack of enzymes or microorganisms. Nevertheless, PE is expected to be degradable by the microorganisms existing in soils from the viewpoint of environmental aspects. Recent studies have reported slight degree of degradation of PE with ordinal molecular weight. ${ }^{1-11}$ The degradation has been carried out for low-density and high-density PE by Albertsson et $a l{ }^{4-11}$ They pointed out that biodegradation of PE is affected by preliminary UV irradiation, by the antioxidants and by additives. ${ }^{1-8}$ Moreover, Otaki et al. reported that the biodegradation of PE becomes significant by the addition of starch..$^{9-11}$

In our previous paper, ${ }^{12}$ we made fundamental study to develop ultra-high molecular weight polyethylene (UHMWPE)-starch composite materials with sufficient high strength and high modulus as well as biodegrad-

${ }^{\dagger}$ To whom correspondence should be addressed. ability. Biodegradation of the composite films was studied using two types of bacteria, Myrothecium verrucaria and Chaetomium globosum. Unfortunately, no biodegradability was found in the PE domain, although more than $80 \%$ of starch components was degraded. Furthermore, we investigated the biodegradation behavior of the uiaxially stretched PE-starch composite films buried in the three types of soils such as paddy soil, farmyard manure and red clay. As the results, it was found that biodegradability of the composite films is dependent on the kinds of soil, burying period, stretching ratio and composition of films. ${ }^{13}$ The changes in the tensile strength and Young's modulus after biodegradation were most prominent in the specimen buried in the red clay. A peak position of differential scanning calorimetry (DSC) for the specimen buried in red clay shifted $5.4^{\circ} \mathrm{C}$ to the lower temperature side in comparison with a peak of the unburied specimen. In scanning electron microscopy (SEM), it was confirmed that the continuous fibrous textures 
disappeared at several regions indicating remarkable chain scission for the 1/5 composite. The drastic decrease in the storage modulus was also confirmed for the composite.

In this study, the biaxially stretched composite films were prepared in accordance with the same gelationcrystallization technique as used in a previous paper. ${ }^{14,15}$ By using these samples, the biodegradability of the composite film samples was estimated. The specimens were buried in the two types of soils, namely, paddy soil and red clay. Interesting biodegradation behavior of PE component was observed for the specimen buried in red clays. Biodegradability of the composite film was estimated by mechanical measurements, SEM, $\mathrm{X}$-Ray and DSC.

\section{EXPERIMENTAL}

\section{Materials}

The original sample materials used in this study were linear UHMWPE with $M_{\mathrm{V}}=6 \times 10^{6}$, which was purchased from Hercules Co. Ltd., and corn starch treated with silane coupling agent, which was obtained from Hagiwara Eng. Co. Ltd.

\section{Sample Preparation}

The high strength and high modulus composite film samples were prepared according to the method described in our previous paper. ${ }^{14}$ The UHMWPE pellets and starch particles were mixed at the desired composition (UHMWPE/starch $=1 / 1$, or $1 / 5$ ). The process of mixing of the UHMWPE and starch was important to obtain a homogeneous dispersion of starch particles in UHMWPE solution. Namely, we obtained good results by mixing starch and UHMWPE powders and then pouring this mixture into decalin at room temperature. This suspension was then heated to $130^{\circ} \mathrm{C}$ and kept for 20 min under nitrogen atmosphere. The UHMWPE dissolved in decalin was set to be $0.9 \%$ (weight percent). This concentration was confirmed to be the best one for obtaining maximum draw ratio for biaxial stretching, ${ }^{13}$ by adjusting the amount of decalin. The homogenized dispersion was quenched by pouring it into an aluminum tray at room temperature to generate gel. Decalin was allowed to evaporate from the gel under ambient conditions. The resultant gel containing more than $200 \%$ of solvent, was pressed to obtain gels with a constant thickness of $500 \mu \mathrm{m}$, and dried further for 2 weeks to remove all traces of decalin.

The dry gel films were cut into a square of $90 \mathrm{~mm} \times$ $90 \mathrm{~mm}$. These films were elongated biaxially at $135^{\circ} \mathrm{C}$ by using an Iwamoto biaxial stretcher under nitrogen atmosphere until the desired draw ratio $(\lambda)$ was ob-
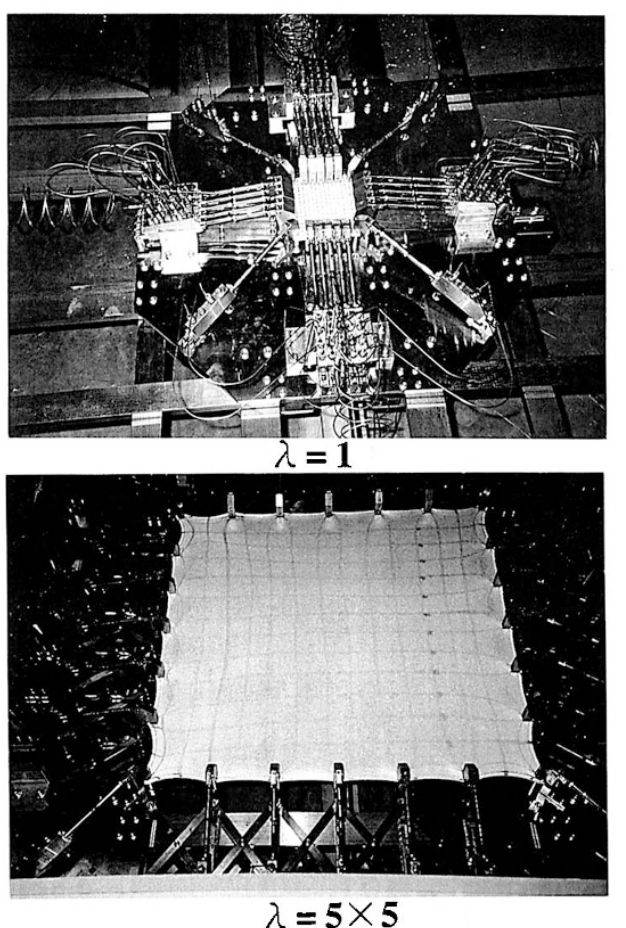

Figure 1. Simultaneous biaxially stretching instrument used in the present experiment.

tained. The biaxially stretching behavior was shown in Figure 1.

\section{Sample Characterization}

Before and after the biodegradation tests, characterization of the composite films was carried out according to the method reported in the previous paper. ${ }^{14}$

SEM photographs were obtained with a JSM-T300 under an accelerating voltage of $1.5 \mathrm{kV}$ for the samples coated with Au. DSC traces of samples were recorded at a constant elevating rate of $10^{\circ} \mathrm{C} \mathrm{min}^{-1}$ with a Rigaku DSC 8230. The complex dynamic tensile moduli were measured at a frequency of $10 \mathrm{~Hz}$ over the temperature range from -150 to $150^{\circ} \mathrm{C}$ by using a viscoelastic spectrometer (VES-R, Iwamoto Machine Co. Ltd.).

$\mathrm{X}$-Ray measurement was carried out by a 12$\mathrm{kw}$ rotating-anode X-Ray generator (Rigaku RAD-rA) with a point focusing, and the monochromatic $\mathrm{Cu}-K_{\alpha}$ radiation (wavelength of $0.154 \mathrm{~nm}$ ) was used. In this condition, an incident beam was collimated by a collimator of $2 \mathrm{~mm}$ in diameter and the diffraction beam was detected by a slit of $0.9 \mathrm{~mm} \times 0.9 \mathrm{~mm}$. Wide angle X-Ray diffraction (WAXD) and small angle X-Ray scattering (SAXS) patterns were taken with a flat camera.

\section{Biodegradation Tests in Soils}

Biodegradation was done for the specimens buried in two kinds of soils, paddy soil and red clay. The specimen $(30 \times 30 \mathrm{~mm}$ in square $)$ was buried in the soil 
Table I. Characteristics of three kinds of soils used (cfu is an abbreviation of colony forming unit per $1 \mathrm{~g}$ soil)

\begin{tabular}{|c|c|c|c|c|c|c|}
\hline \multirow{2}{*}{ Soil type } & \multirow{2}{*}{ Sampling date } & \multicolumn{2}{|c|}{ Underground $(10 \mathrm{~cm})$} & \multirow{2}{*}{$\frac{\text { Number of bacteria }}{(\mathrm{cfu} / \mathrm{g} \text { soil })}$} & \multirow{2}{*}{$\frac{\text { Number of actinomyces }}{(\mathrm{cfu} / \mathrm{g} \text { soil })}$} & \multirow{2}{*}{$\frac{\text { Number of Fungi }}{\text { (cfu/g soil) }}$} \\
\hline & & Temp. $/{ }^{\circ} \mathrm{C}$, & $\overline{\mathrm{pH}}$ & & & \\
\hline \multirow{3}{*}{ Paddy soil } & Aug. 18. 1994 & 36.5 & \multirow{3}{*}{6.8} & $5.0 \times 10^{8}$ & $3.5 \times 10^{6}$ & \\
\hline & Oct. 23. 1994 & 25.3 & & $1.1 \times 10^{8}$ & $4.7 \times 10^{5}$ & \\
\hline & Mar. 10. 1995 & 13.0 & & $4.2 \times 10^{7}$ & $1.0 \times 10^{5}$ & \\
\hline \multirow{3}{*}{ Red clay } & Aug. 18. 1994 & 35.5 & \multirow{3}{*}{4.7} & $2.1 \times 10^{7}$ & $7.1 \times 10^{5}$ & $1.2 \times 10^{7}$ \\
\hline & Oct. 23. 1994 & 24.5 & & $1.2 \times 10^{7}$ & $2.1 \times 10^{5}$ & $8.8 \times 10^{6}$ \\
\hline & Mar. 10. 1995 & 10.5 & & $5.0 \times 10^{5}$ & $3.7 \times 10^{4}$ & $1.1 \times 10^{5}$ \\
\hline
\end{tabular}

Table II. Separated fungus in red clay and paddy soil

\begin{tabular}{clcl}
\hline Soil type & Separated fungus & Number of colonies & Color \\
\hline \multirow{5}{*}{ Red clay } & Penicillium $s p$. & 10 & Pink \\
& Penicillium $s p$. & 2 & Brown \\
& Penicillium $s p$. & 1 & Pink and brown \\
& Penicillium $s p$. & 2 & Green \\
& Un-identified & 1 & White \\
& Aspergillus $s p$. & 2 & Light green \\
& Aspergillus $s p$. & 1 & Black \\
& Cladosporidium $s p$. & 3 & Black \\
& Mucor sp. & 1 & Gray \\
Paddy soil & Penicillium $s p$. & 2 & Green \\
& Cladosporidium $s p$. & 1 & Black \\
\hline \multirow{2}{*}{ Total } & & 26 & - \\
\hline
\end{tabular}

at $10 \mathrm{~cm}$ depth for 16 months from June 1st in 1995 to September 30th in 1996. Characterizations of two kinds of soil are summarized in Table I and II. In Table I, the temperature in soil varies with the season and the temperature difference between summer and winter is more than $20^{\circ} \mathrm{C}$. The $\mathrm{pH}$ value also varies with the kinds of soil. Propagation of microorganisms was estimated for bacteria, actinomyces, and fungi but the further detailed classification could not be done except fungi. Anyway, the progression is active in summer and this tendency is more remarkable in paddy soil. The progression of three kinds of microorganisms is the least in the red clay. The further classification was done for fungi in red clay, since the biodegradation was most remarkable in red clay. The results are listed in Table II.

Sampling was done at October 1st in 1996 and the weight losses were simply evaluated by measuring the weight of film before and after degradation. Weight loss is expressed as follows:

$$
\text { Weight Loss }=\left(W_{\mathrm{d}}-W_{\mathrm{o}}\right) / W_{\mathrm{d}} \times 100
$$

where $W_{\mathrm{d}}$ and $W_{\mathrm{o}}$ are the weights of films before and after the degradation, respectively. Storage modulus, DSC trace and SEM morphology of the specimens were examined by the methods described elsewhere. ${ }^{12}$

\section{RESULTS AND DISCUSSION}

\section{Characteristitcs of Original (no biodegradation) Films}

Figure 2 shows small SAXS patterns for the undrawn dry gel films, when the incident beam was directed parallel to the film surface (end view). The SAX patterns from the UHMWPE homo-polymer show the meridional scattering having scattering maxima. The corresponding WAXD pattern revealed the preferential orientation of the $c$-axes perpendicular to the film surface, although it was not shown in this paper. The SAXS and WAXD patterns together indicate that the dried gel film is composed of crystal lamellae that are oriented with their large flat faces parallel to the film surface and within the lamellar crystals constituting the gel, the $c$-axes are oriented perpendicular to the large flat faces. With increasing the starch content, the SAXS patterns show a circular type indicating a random orientation of crystal lamellae.

Figure 3 show WAXD patterns from UHMWPE homo-polymer and the $1 / 5$ blend with $\lambda=2 \times 2$ and $5 \times 5$. For UHMWPE homo-polymer, the patterns reveal that the (110) and (200) planes take preferential orientation but crystallites within the $1 / 5$ blend take a random orientation even at $\lambda=5 \times 5$. This indicates that large amount of starch hamper the preferential orientation of the crystal planes parallel to the film surface. 


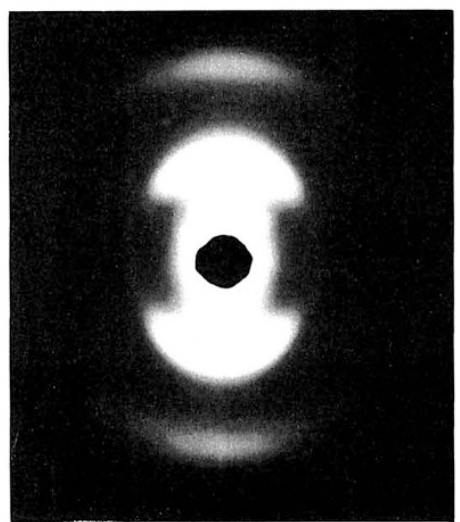

(a) $\mathbf{1 / 0}$

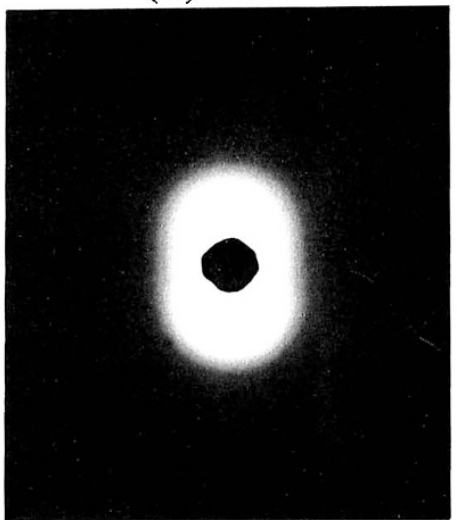

(b) $3 / 1$

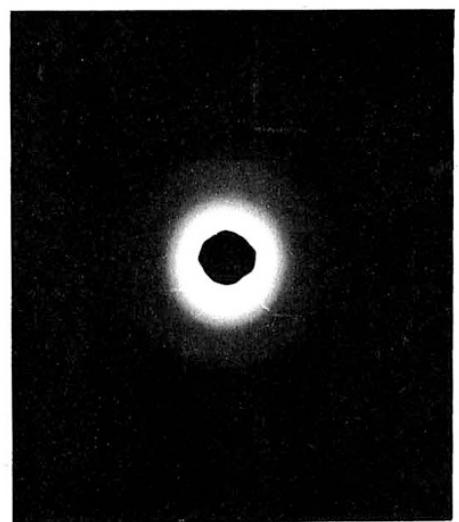

(c) $1 / 1$

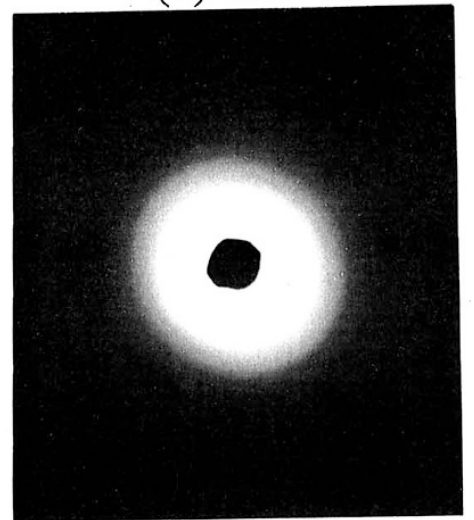

(d) $1 / 5$

Figure 2. SAXS patterns (end view) for the blends with various compositions.

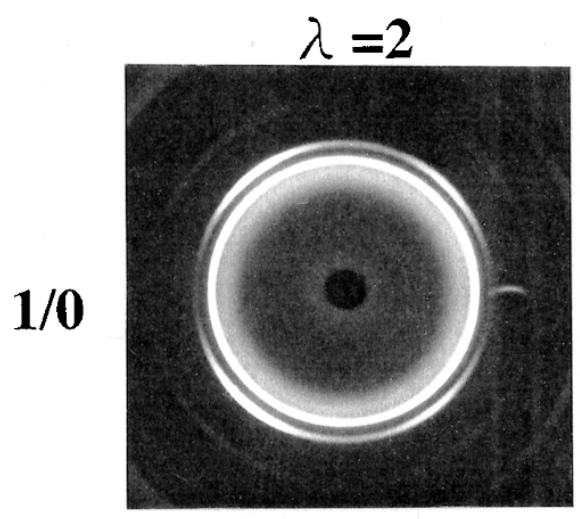

(a)

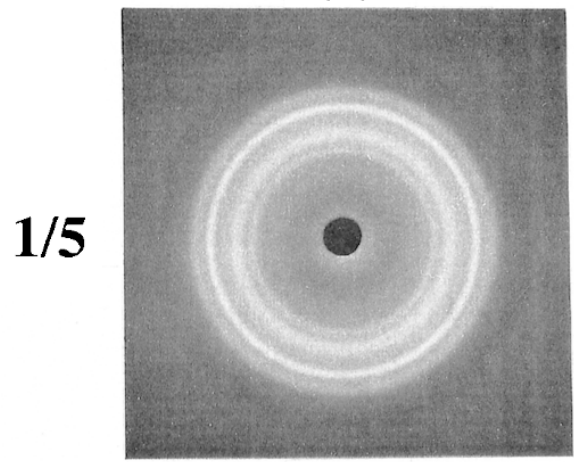

(b)

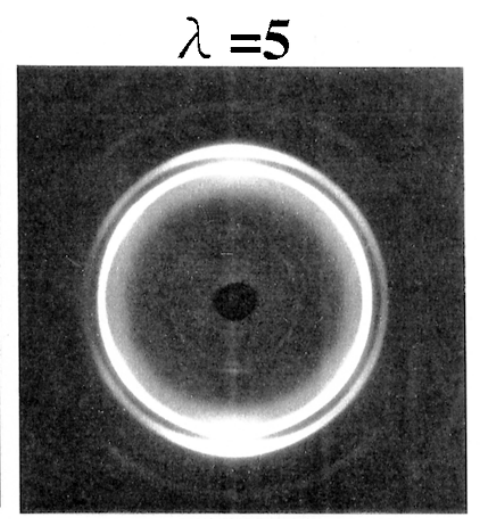

(c)

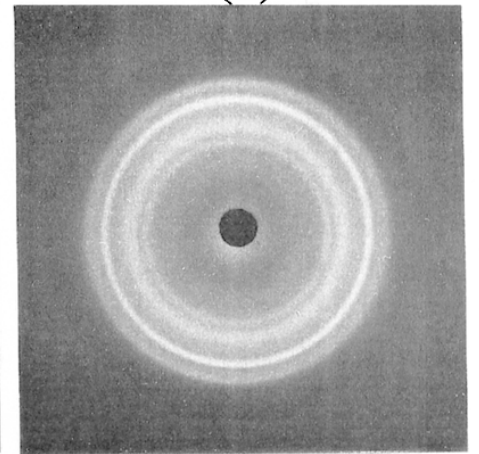

(d)

Figure 3. WAXD patterns (end view) for UHMWPE and the $1 / 5$ blend with $\lambda=1$ and $2 \times 2$. 
Table III. Weight losses of the film samples after buried for 16 months in two kind of soils

\begin{tabular}{cccccc}
\hline \multirow{2}{*}{ Soil type } & $\begin{array}{c}\text { Composition } \\
\text { (PE/ST) }\end{array}$ & \multicolumn{4}{c}{ Weight loss $(\%)$} \\
& $1.0 \times 1.0$ & $1.5 \times 1.5$ & $2.0 \times 2.0$ & $3.0 \times 3.0$ \\
\hline \multirow{2}{*}{ Paddy soll } & $1 / 1$ & 42.6 & 44.6 & 46.3 & 48.7 \\
& $1 / 5$ & 72.7 & 74.1 & 75.8 & 78.3 \\
\multirow{2}{*}{ Red clay } & $1 / 1$ & 39.4 & 42.3 & 45.0 & 45.8 \\
& $1 / 5$ & 68.8 & 71.2 & 73.4 & 74.1 \\
\hline
\end{tabular}

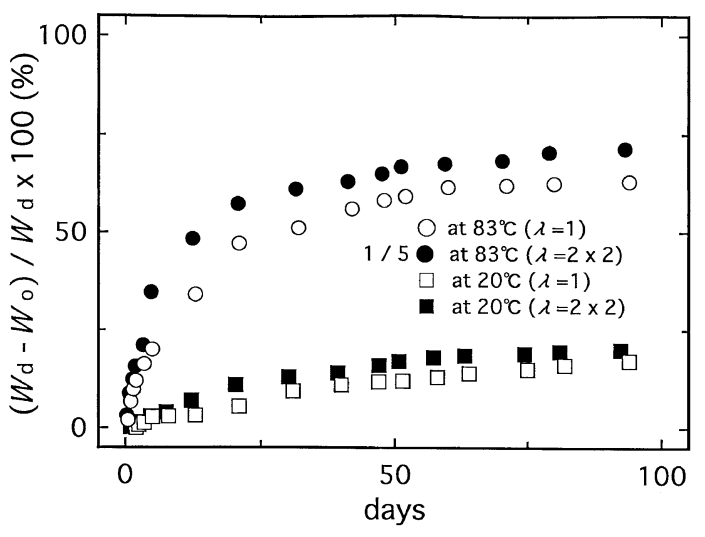

Figure 4. Change in weight of the film treated with water at 23 and $83^{\circ} \mathrm{C}$, where $W_{\mathrm{d}}$ is the weight of dry film and $W_{\mathrm{o}}$ is the weight of the film vacuum dried after removal from the water bath.

Of course, it seems that the chain axes are oriented parallel to the film surface. However, this behavior cannot be confirmed by birefringence, since the existence of large amount of starch hamper the transmission of light under polarized microscopy.

Before the biodegradation, the specimens were immersed in water baths at 23 and $83^{\circ} \mathrm{C}$ for 100 days to check the solubility of starch particles within the $1 / 5$ blends with $\lambda=1$ and $2 \times 2$. Figure 4 shows the results, in which $W_{\mathrm{d}}$ is the weight of the original dry gel film and $W_{\mathrm{o}}$ is the weight of film vacuum dried after removal from water bath. The value of $\left(W_{\mathrm{d}}-W_{\mathrm{o}}\right) / W_{\mathrm{d}}$ increases day by day; indicating that starch particles were dissolved in water, due to penetration of water molecules into the gaps between polyethylene fibrils. However, this value is not serious for the biodegradation experiments, since the amount of starch dissolved in water at $23^{\circ} \mathrm{C}$ was less than $25 \%$. The environment in the ground is quite different from such a serious environment in that a piece of film was immersed in large amounts of water for $100 \mathrm{~d}$. It seems that most of starch particles would not dissolve in the small amount of water in the ground used for biodegradation.

\section{Results on the Biodegradation Tests}

Biodegradation was carried out by the methods described in the Experimental section. Two kinds of soil, paddy soil, and red clay were adopted. Undrawn $(\lambda=1 \times 1),(1.5 \times 1.5),(2.0 \times 2.0)$, and $(3.0 \times 3.0)$ with

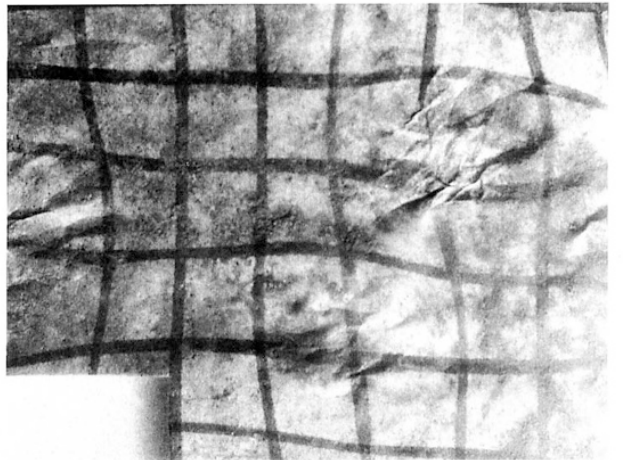

(a)

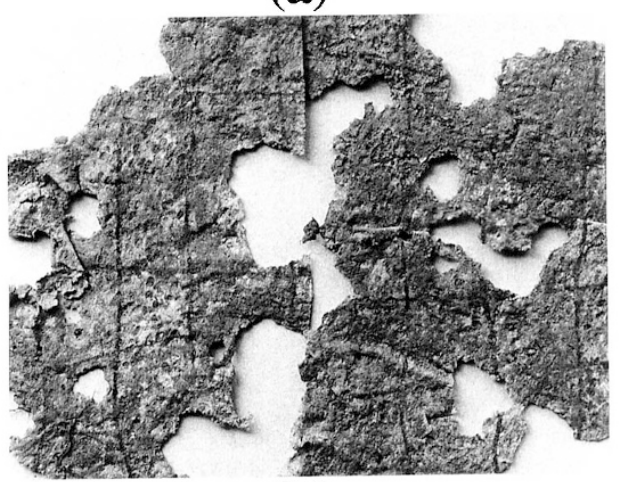

(b)

Figure 5. Photographs of the biaxially stretched films with $\mathrm{PE} / \mathrm{ST}$ (1/5 Composition) and with draw ratio of $2 \times 2$ buried in soils for 16 months. (a) Paddy soil; (b) Red clay.

PE/ST compositions of $1 / 1$ and $1 / 5$ were used as test specimens. Weight losses of the sample films buried for 16 months are shown in Table III. Weight losses are found to be dependent mainly on the contents of starch, suggesting that the starch particles are mainly degraded in these soils. Weight loss increased as the draw ratio increases. In addition, degradation rate of film samples buried in red clay was lower than that in paddy soil. After 16 month burying, more than $80 \%$ of the starch components were degraded in almost all the samples.

In Figure 5, photographs of the 1/5 composite films $(\lambda=2 \times 2)$ are shown for the sample buried in paddy soil (a) and that in red clay (b) for 16 month. Prominent change is seen for the sample buried in red clay. Some holes, which must have been generated by the degradation of the component polymers, can be observed. This result is of quite interest, since the weight loss 


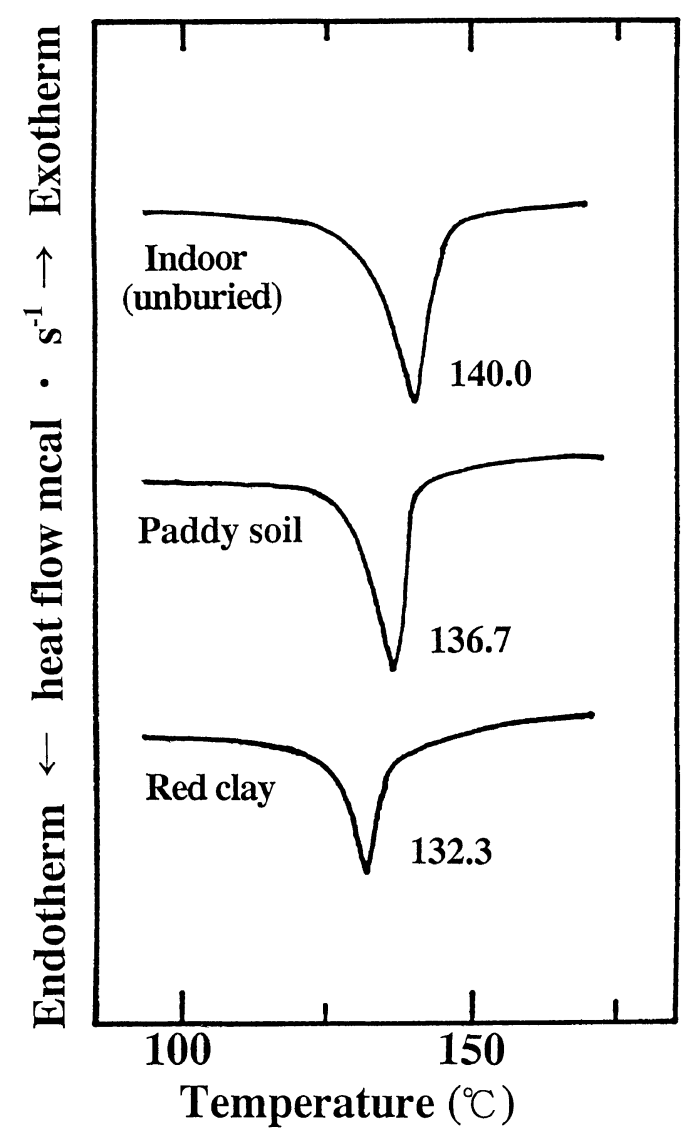

Figure 6. $\mathrm{DSC}$ traces of the films with $\mathrm{PE} / \mathrm{ST}=1 / 5$ and draw ratio of $2 \times 2$ after burying in two kinds of soils for 16 month: Indoor (unburied); Paddy soil; Red clay.

of the sample buried in red clay was lower than that in paddy soil. Same tendency was confirmed for uniaxially stretching films (see Figure 2 in ref 13). Therefore, we further investigated the changes in mechanical, thermal and visco-elastic properties of the buried specimens.

Thermal behavior was examined and the results of DSC traces are shown in Figure 6. The DSC trace of the sample buried in red clay changed drastically compared from that of the unburied (indoors). The peak position of DSC endotherm for the sample buried in red clay shifted $7.7^{\circ} \mathrm{C}$ to lower temperature side, which is much higher than that in paddy soil $\left(3.3^{\circ} \mathrm{C}\right)$. This is due to the drastic decrease in crystal size and the same phenomenon was confirmed for uniaxially stretched blend films with $1 / 5$ composition. ${ }^{13}$ This suggests that crystallites of UHWPE were disrupted by enzyme secreted by bacteria and actinomyces in the red clay and/or by oxidizing substances occurred by decomposition of starch in the red clay. If the disruption is due to the oxidation substances existed in the red clay, the peak shifts must be observed for UHMWPE homo-polymer buried in the red clay. However, such behavior was not confirmed for the UHMWPE film.

Figure 7 shows temperature dependence of the stor-

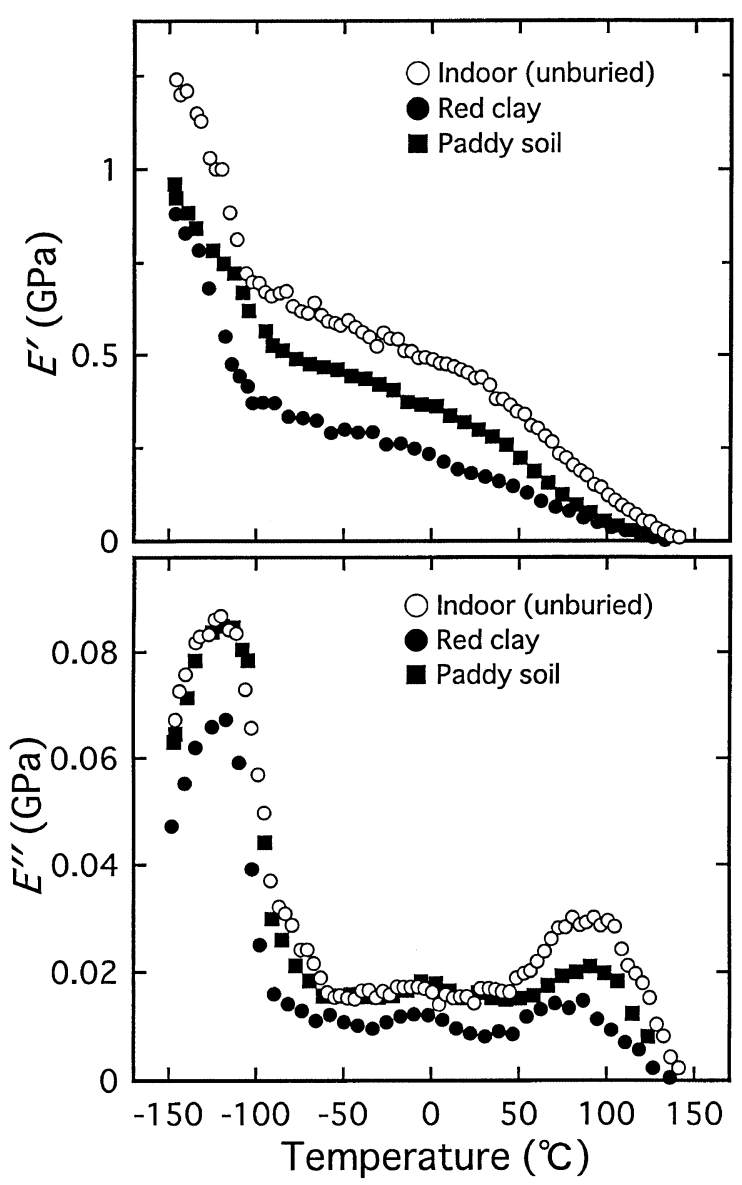

Figure 7. Temperature dependence of the storage modulus and loss modulus for the films with $\mathrm{PE} / \mathrm{ST}=1 / 1$ and draw ratio of $2 \times 2$ after burying in two kinds of soils for 16 month: Indoor (unburied); Paddy soil; Red clay.

age modulus $\left(E^{\prime}\right)$ and loss modulus $\left(E^{\prime \prime}\right)$ of the $1 / 1$ composite films buried in red clay and in paddy soil for 16 months and unburied (indoor) and Figure 8 shows temperature dependence of $E^{\prime}$ and $E^{\prime \prime}$ of the $1 / 5$ composite films. The measurements were done for the some local parts within the specimen. Namely, significant disruption part within the specimen must be avoided to carry out the measurements. From the results for uniaxially stretching films, ${ }^{13}$ drastic decrease in $E^{\prime}$ observed for the specimens after the biodegradation indicates chain scission of UHMWPE. Especially, the decrease was remarkable for the $1 / 5$ blend buried in red clay indicating significant biodegradation. For the loss modulus, three dispersion peaks could be observed. ${ }^{16}$ The $\alpha$ transition associated with crystal dispersion can be observed around $80^{\circ} \mathrm{C}$ for all the specimens and the peak intensity of samples buried in soils becomes lower than that of the unburied sample. The peak height becomes lowest for the sample buried in red clay, reflecting low magnitude of $E^{\prime}$. The $\beta$ transition appearing in the temperature range from -20 to $10^{\circ} \mathrm{C}$ could be observed slightly for the specimen with no biodegradation, indicating that large amount of starch hamper sig- 


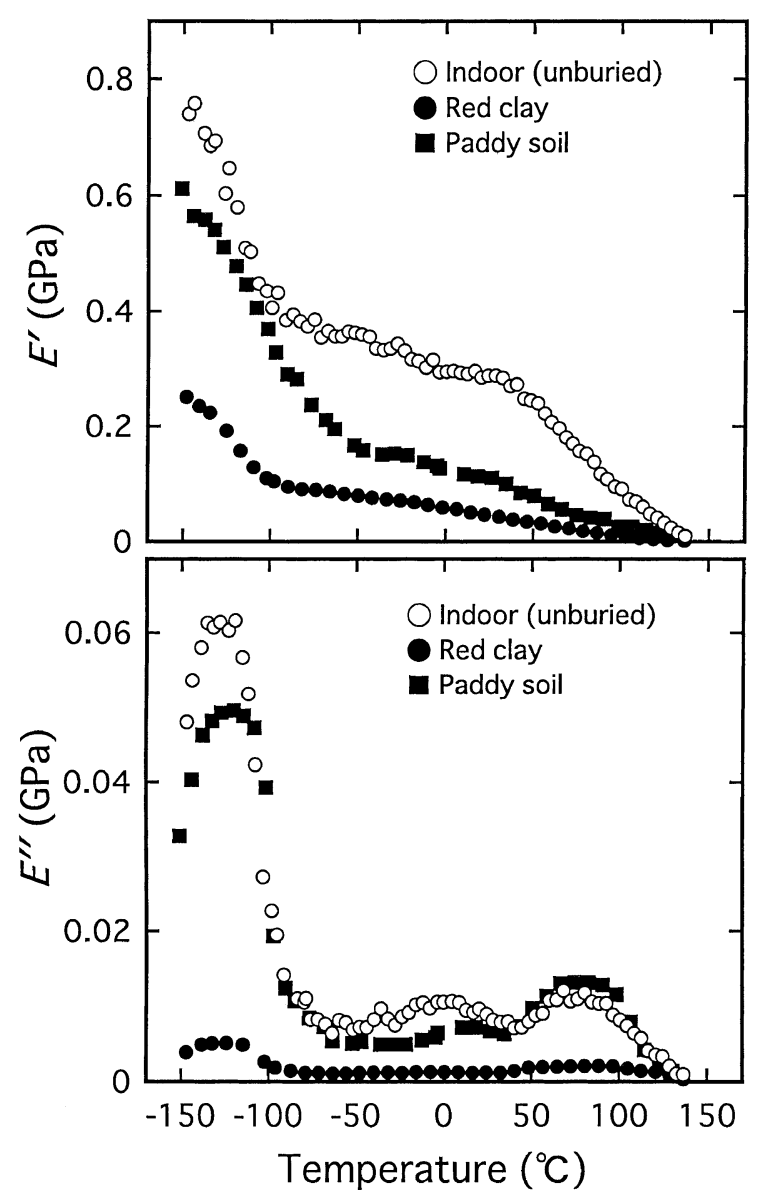

Figure 8. Temperature dependence of the storage modulus and loss modulus for the films with $\mathrm{PE} / \mathrm{ST}=1 / 5$ and draw ratio of $2 \times 2$ after burying in two kinds of soils for 16 month: Indoor (unburied); Paddy soil; Red clay.

nificant crystallization of UHMWPE. The $\gamma$ transition appearing around $-130^{\circ} \mathrm{C}$ is due to the local motion associated with the amorphous phase. ${ }^{16}$ The peak height is also lowest for the specimen buried in red clay, which is related to the lower values of the corresponding $E^{\prime}$ at these temperature range.

SEM observation was carried out for the samples with draw ratio of $2 \times 2$ buried for 16 months in red clay. The micrographs of the unburied and buried samples are shown in Figure 9a and 9b, respectively. Morphological changes are clear after degradation not only in the starch domain but also in the UHMWPE domain. Namely, the large voids between fibrous texture are seen in Figure 9b, indicating the chain scission of PE by remarkable biodegradation. However, and scission of fibrous textures could not be observed directly, as has been observed for uniaxially stretching films. ${ }^{13}$ Even so, the morphological change in Figure 9 is confirmed to be more drastic in comparison with that for the specimen buried in paddy soil. Judging from the drastic decrease in the storage modulus $\left(E^{\prime}\right)$ in Figure 8, the large voids is thought to be due to the biodegra-

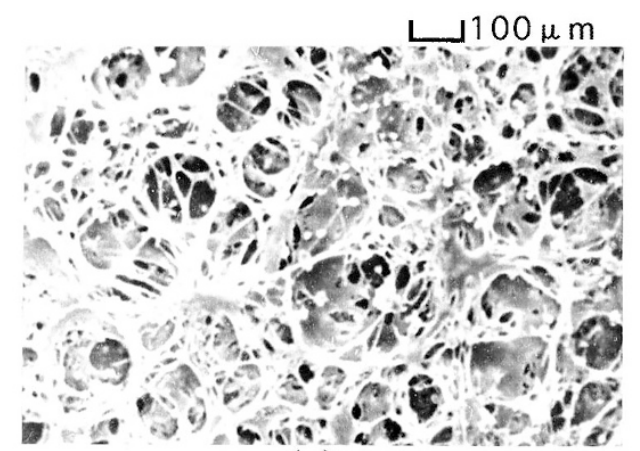

(a)

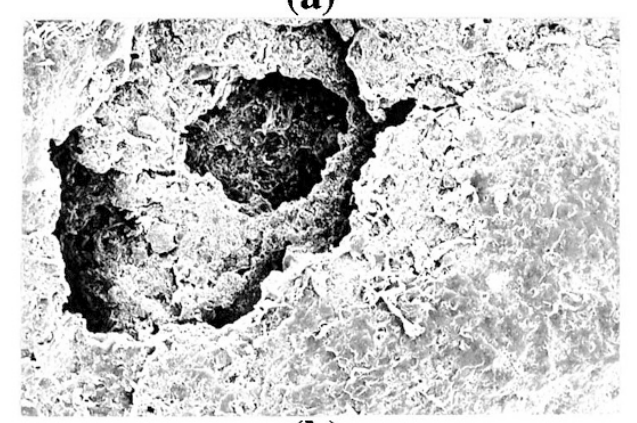

(b)

Figure 9. Scanning electron micrographs of the $1 / 5$ blend with $\lambda=2 \times 2$. (a) Unburied; (b) After burying in red clay for 16 months.

dation of UHMWPE. Incidentally, any chain scission could not be observed within the PE film (1/0) buried in red clay. That is, any shape change between buried and unburied specimens was not observed. Even so, it is quite distinct that the dispersed starch component induced the biodegradation of PE domain in the composite films buried in red clay. The biodegradability of PE components in red clay must have been caused by the attack of some bacteria or fungi existing in red clay.

\section{CONCLUSION}

The composite films of PE with ultrahigh molecular weight $\left(6 \times 10^{6}\right)$ and starch were prepared by gelationcrystallization from dilute solutions of $\mathrm{PE}$, in which starch particles were dispersed. The PE-starch compositions chosen were $1 / 1$ and $1 / 5$. The maximum draw ratio of the $1 / 5$ blend reached $3 \times 3$. Most of starch particles were maintained within the composite films, despite of such high draw ratio.

Biodegradation of the composite films was examined in two kinds of soils. The weight loss for the sample buried in paddy soil was higher than that in red clay. The changes in the mechanical properties after the degradation, however, were prominent in the sample buried in red clay. Drastic morphological changes were observed under SEM for the specimen buried in red clay, indicating that biodegradation surely occurred in the PE domain. This was in good agreement with the results of $E^{\prime}, E^{\prime \prime}$, and DSC measurements. However, 
no degradation could be observed for the UHMWPE homo-polymer (1/0) dry gel films with $\lambda=2 \times 2$. Therefore, it is obvious that the dispersed starch component induced biodegradation of PE domain in the composite films buried in red clay.

\section{REFERENCES}

1. A. C. Albertsson and B. Ranby, "Proceedings of Che 3rd Internationa Biodegradation Symposium", J. M. Sharpley and A. M. Kaplan, Ed., Elsevier Science, London, 1976, p 743.

2. A. C. Albertsson, Eur. Polym. J., 16, 623 (1980).

3. A. C. Albertsson, J. Appl. Polym. Sci., 35, 1289 (1988).

4. A. C. Albertsson, J. Appl. Polym. Sci., 22, 3419 (1978).

5. A. C. Albertsson, Z. G. Banhidi, and L.-L. Beyer-Eriksson, J. Appl. Polym. Sci., 22, 3434 (1978).

6. A. C. Albertsson and Z. G. Banhidi, J. Appl. Polym. Sci., 25, 1665 (1980).

7. A. C. Albertsson and B. Ranby, Appl. Polym. Symp., 35, 423 (1979).
8. A. C. Albertsson, "Eighth Ann. Conf. Ad. Stabilization and Controlled Degradation of Polym.”, Lucerne, May, 1986.

9. Y. Otake, Y. Gomi, T. Kobayashi, S. Ito, and K. Hyakutake, Journal of the Society of Rubber Industry, Japan (NihonGomu-Kyokaishi), 64, 55 (1991).

10. Y. Otake, T. Kobayashi, S. Ito, H. Asabe, M. Yabuki, and K. Ono, Journal of the Society of Rubber Industry, Japan (NihonGomu-Kyokaishi), 67, 82 (1994).

11. Y. Otake, T. Kobayashi, H. Asabe, N. Murakami, and K. Ono, Appl. Polym. Sci., 56, 1789 (1995).

12. T. Nakashima and M. Matsuo, J. Macromol. Sci., Phys., B35, 659 (1996).

13. T. Nakashima, H. Ito, and M. Matsuo, J. Macromol. Sci., Phys., B41(1), 1 (2001).

14. T. Nakashima, C. Y. Chu, Y. Bin, and M. Matsuo, Polym. J. 3354 (2001)

15. T. Nakashima, C. Y. Xu, Y. Bin, and M. Matsuo, Int. J. Polym. Mater, (in press).

16. R. A. V. Raff, "In Encyclopedia of Polymer Science and Technology”, H. F. Mark et al., Ed., John Wiley \& Sons, Inc., New York, N.Y., 1967, pp 275-332. 